\title{
Grape seed extract supplementation attenuates the heat stress-induced responses of jejunum epithelial cells in Simmental $\times$ Qinchuan steers
}

\author{
Xiaomin $\mathrm{Li}^{1}$, You Yang ${ }^{1}$, Shimin $\mathrm{Liu}^{2}$, Jing Yang ${ }^{1}$, Cheng Chen ${ }^{1}$ and Zhihong Sun ${ }^{1 *}$ \\ ${ }^{1}$ Key Laboratory for Bio-feed and Molecular Nutrition, Southwest University, Chongqing 400715, People's Republic of China \\ ${ }^{2}$ Faculty of Natural and Agricultural Sciences, The University of Western Australia, Crawley, Western Australia 6009, \\ Australia \\ (Submitted 29 May 2013 - Final revision received 3 March 2014 - Accepted 18 March 2014 - First published online 20 May 2014)
}

\section{Abstract}

Grape seed extract (GSE), a rich source of polyphenols, is reported to possess antioxidant, anti-inflammatory and immunomodulatory properties. The objective of the present study was to determine whether GSE could attenuate the heat stress-induced responses of jejunum epithelial cells (JEC) in cattle. The JEC of a steer (Simmental $\times$ Qinchuan) were exposed to heat stress for $2 \mathrm{~h}$ in the absence $(0 \mu \mathrm{g} / \mathrm{ml})$ or presence $(10,20,40$ and $80 \mu \mathrm{g} / \mathrm{ml})$ of GSE in the culture medium. When cultured at $40^{\circ} \mathrm{C}$, JEC supplemented with GSE exhibited increased glutathione peroxidase activity $(P=0.04)$, viability $(P=0.004)$, and mRNA expression of epidermal growth factor $(E G F ; P=0 \cdot 03)$ and EGF receptor $(E G F R ; P=0.01)$. Under the same conditions, the cells exhibited decreased mRNA expression of $I L-8(P=0.01)$ and $T N F-\alpha$ $(P=0.03)$ and decreased protein concentrations of IL-1 $\beta(P=0.02)$, Toll-like receptor 4 (TLR $4 ; P=0.04)$ and heat shock protein 70 (HSP70; $P<0 \cdot 001$ ). When cultured at $43^{\circ} \mathrm{C}$, JEC supplemented with GSE exhibited increased catalase activity $(P=0 \cdot 04)$, viability $(P<0.001)$, and mRNA expression of $E G F(P<0.001)$ and $E G F R(P<0.001)$ and decreased protein concentrations of IL-1 $\beta(P<0 \cdot 001)$, TLR4 $(P=0.03)$ and HSP70 $(P<0.001)$, as well as mRNA expression of $I L-8(P<0.001)$, TLR4 $(P=0.002)$ and TNF- $\alpha(P<0 \cdot 001)$. Temperature $\times$ GSE concentration interactions were also observed for the concentrations of IL-1 $\beta(P<0 \cdot 001)$, IL- $8(P<0 \cdot 001)$, TNF- $\alpha$ $(P=0.01)$ and $\operatorname{HSP70}(P=0.04)$ and viability $(P<0.001)$ of JEC. The results of the present study indicate that GSE can attenuate the responses of JEC induced by heat stress within a certain range of temperatures.

\section{Key words: Immune responses: Grape seed extract: Jejunum epithelial cells: Heat stress: Steers}

High dry-bulb temperature and humidity, in combination with a solar load and low air movement, can exceed stressor limits, resulting in reduced animal productivity and impaired animal well-being ${ }^{(1)}$. Baumgard \& Rhoads ${ }^{(2)}$ have reported that heat stress markedly alters post-absorptive carbohydrate, lipid and protein metabolism independent of reduced feed intake through coordinated changes in fuel supply and utilisation by multiple tissues. Apart from its direct effects on nutrient intake and metabolism, much of the detrimental effects of heat stress on animal productivity may be indirectly mediated by reduced antioxidant capacity, inappropriate hormone secretions, and increased susceptibility to parasites and disease occurrence ${ }^{(3-5)}$.

In addition to functioning as the primary site of nutrient absorption, the gastrointestinal tract is also an important component of the immune system ${ }^{(6-8)}$. The ambient temperature clearly affects the physiological functions of the gastrointestinal tract. Heat-stressed mammals channelise blood to the periphery of their body in an attempt to maximise radiant heat dissipation, and this blood redistribution is accompanied by vasoconstriction of the gastrointestinal tract ${ }^{(9)}$. As a result, reduced blood and nutrient flow results in hypoxia at the intestinal epithelium, which ultimately compromises intestinal integrity and function ${ }^{(10)}$. Consequently, heat-induced intestinal permeability is associated with the increased abundance of blood markers of endotoxaemia, hypoxia and inflammation, all of which may contribute to the multi-organ failure syndrome ${ }^{(11)}$. Damage to the mucosal epithelium of the small intestine caused by heat stress ${ }^{(12)}$ can directly affect intestinal barrier function and nutrient absorption in the small intestine ${ }^{(13,14)}$, resulting in reduced growth performance.

Management strategies are required to alleviate heat stress. Beede \& Collier ${ }^{(15)}$ have identified three management strategies that minimise the effects of thermal stress: physical modification of the living environment; breeding of animals for heat tolerance; improvement of nutritional management.

Abbreviations: CAT, catalase; DMEM-FBS, Dulbecco's modified Eagle's medium with 10\% fetal bovine serum; EGF, epidermal growth factor; EGFR, epidermal growth factor receptor; GSE, grape seed extract; GSH, glutathione; GSH-Px, glutathione peroxidase; HSP70, heat shock protein 70; JEC, jejunum epithelial cells; SERCA2a, sarco(endo)plasmic reticulum $\mathrm{Ca}^{2+}$-ATPases 2a; SOD, superoxide dismutase; TLR, Toll-like receptor. 
Limiting energy intake has been proven to effectively decrease heat generation ${ }^{(16)}$ and thereby decrease overall metabolic heat load in animals subjected to high ambient temperatures. In addition, dietary manipulation to enhance the antioxidant capacity of the body has been proven to be an important measure in the alleviation of heat stress. Certain trace minerals (such as cofactors of antioxidant enzymes such as Se in glutathione peroxidase (GSH-Px)) and several vitamins (such as vitamins $\mathrm{E}$ and $\mathrm{C}$ ) are integral components of the antioxidant system $^{(17)}$ and have heat stress-lowering effects ${ }^{(18)}$.

In recent years, there has been growing interest in the use of grape seed extract (GSE) as a dietary antioxidant supplement ${ }^{(19)}$. The antioxidant capacity of GSE is due to the presence of high proportions of phenolic compounds, primarily monomeric catechin and epicatechin, gallic acid, and oligomeric and polymeric procyanidins in grapes ${ }^{(20)}$. Previous studies have reported that GSE possesses strong antioxidant capacity in vitro - 20- and 50-fold greater than that of vitamins $\mathrm{E}$ and $\mathrm{C}$, respectively ${ }^{(21-23)}$ - in addition to immunomodulatory functionality ${ }^{(24)}$. The present study was carried out to investigate the effects of GSE on the antioxidant capacity and immune status of jejunum epithelial cells (JEC) isolated from a steer subjected to heat stress treatment.

\section{Materials and methods}

The present experiment was conducted according to the Animal Care and Use Guidelines of the Southwest University, Chongqing, China.

\section{Preparation of jejunum epithelial cells}

The methods followed for JEC isolation were based on the procedures described by Sun et al. ${ }^{(25)}$. Briefly, the jejunum epithelia collected from a Simmental $\times$ Qinchuan steer (about $500 \mathrm{~kg}$ body weight) were washed with (1) rinsing solution $1\left(5 \times 10^{5}\right.$ IU/l of penicillin $G$ sodium and streptomycin sulphate) and (2) rinsing solution $2(250 \mu \mathrm{g} / \mathrm{ml}$ of gentamicin and $12.5 \mu \mathrm{g} / \mathrm{ml}$ of amphotericin B). Subsequently, the sample was minced into small pieces, placed in a $200 \mathrm{ml}$ Erlenmeyer digestion flask containing $50 \mathrm{ml}$ of a digestion solution ( $0 \cdot 25 \%$ trypsin and $0.02 \%$ EDTA) and incubated in a low orbital, hot-air incubator at $37^{\circ} \mathrm{C}$ for $30 \mathrm{~min}$. The digestion solution containing pieces of the tissue sample was mixed using a drip pipe for $3 \mathrm{~min}$. After incubation, this mixture was transferred to a $50 \mathrm{ml}$ centrifuge tube containing Dulbecco's modified Eagle's medium with $10 \%$ fetal bovine serum (DMEM-FBS) and centrifuged at $600 \mathrm{~g}$ for $5 \mathrm{~min}$ at room temperature. The supernatant was collected and used for Ig assay. The precipitate containing JEC was washed four times with sterile Hanks' balanced salt solution with an antibiotic-antimycotic mixture $\left(1 \times 10^{5} \mathrm{IU} / 1\right.$ of penicillin $\mathrm{G}$ sodium, $1 \times 10^{5} \mathrm{IU} / 1$ of streptomycin sulphate and $0.25 \mathrm{mg} / \mathrm{ml}$ of amphotericin $\mathrm{B}$ as Fungizone).

\section{Grape seed extract treatment and heat stress exposure}

Based on the time difference in cell adhesion between the fibroblasts and JEC, the cells were cultured for $1.5 \mathrm{~h}$ in DMEM-FBS.
The cells were then transferred to a twenty-four-microwell plate at a density of $1 \times 10^{6}$ cells/plate in DMEM-FBS and cultured for $24 \mathrm{~h}$ under standard conditions at $37^{\circ} \mathrm{C}$ in a $5 \% \mathrm{CO}_{2^{-}}$ humidified atmosphere. After $24 \mathrm{~h}$ of culturing, the plated cells were washed with DMEM-FBS and cultured for an additional $10 \mathrm{~h}$ in DMEM-FBS supplemented with GSE (Tarac Technologies) at a final concentration of $0,10,20,40$ or $80 \mu \mathrm{g} / \mathrm{ml}$ at $37^{\circ} \mathrm{C}$. According to the manufacturer's product description, the GSE contained $90 \cdot 1 \%(\mathrm{w} / \mathrm{w})$ polyphenols, $5.0 \%(+)$-catechin, $4 \cdot 8 \%(-)$-epicatechin, $2 \cdot 4 \%(-)$-epigallocatechin, $14 \cdot 1 \%$ dimeric proanthocyanidins, $11.6 \%$ trimeric proanthocyanidins, $7 \cdot 8 \%$ tetrameric proanthocyanidins and $40.0 \%$ polymeric proanthocyanidins. The doses of GSE added to the culture medium in the present study were determined by referring to the doses used in the studies of Kaur et al. ${ }^{\text {(26) }}$ and Roy et $a l .{ }^{(27)}$. The cultured plates were carefully sealed and placed in a water-jacketed incubator with humidified air mixed with $5 \% \mathrm{CO}_{2}$. There were forty-eight replicates for each level of GSE treatment, and a total of 240 replicates for five GSE concentrations were cultured at a time.

Following GSE-supplemented culturing, the cells were subjected to heat stress treatment. The forty-eight replicates of each level of GSE treatment were further cultured at temperatures of $37^{\circ} \mathrm{C}$ (normal temperature for cell culture), 40, 43 and $46^{\circ} \mathrm{C}$ for $2 \mathrm{~h}$. Temperatures of 40,43 and $46^{\circ} \mathrm{C}$ were selected to reflect temperatures potentially causing slight, harmful and serious or lethal heat stress to cells, respectively. The entire experiment consisted of five GSE concentrations crossed with four temperatures, forming a $5 \times 4$ factorial design with twelve replicates for each treatment. All the replicates were obtained on the same day.

After $2 \mathrm{~h}$ of incubation, four replicates in each treatment were removed and Alamar Blue solution was added to determine cell viability as described below. Additionally, four replicates were preserved at $-80^{\circ} \mathrm{C}$ after treatment with the TRIzol reagent (Invitrogen) for isolating RNA, and the remaining four replicates were used for various assays described below.

\section{Alamar Blue assay for cell viability}

Cell viability was measured according to the procedures described by Byth ${ }^{(28)}$. Alamar Blue solution was added directly into the plate to a final concentration of $10 \%$, and the plate was further incubated at $37^{\circ} \mathrm{C}$ for $3 \mathrm{~h}$. After the incubation period, fluorescence measurements were performed using a fluorescence reader (ELISA module, Anthos microplate spectrophotometer Zenyth 200; Anthos Labtec Instruments, $\mathrm{GmbH}$ ) with the excitation/emission wavelengths set at 570/ $630 \mathrm{~nm}$, the sensitivity gain at 50, and the temperature at $37^{\circ} \mathrm{C}$. Cell viability (\%) was calculated by the equation derived by Willard et al. ${ }^{(29)}$.

\section{Antioxidant enzyme activity assays}

The superoxide dismutase (SOD), catalase (CAT) and GSH-Px activities, as well as malondialdehyde concentration, of JEC were determined using the appropriate assay kits (Jiancheng Bioengineering Institute) according to the manufacturer's 
instructions. The nitrite colouration method was used to determine SOD activity at an excitation wavelength of $550 \mathrm{~nm}$ by measuring the absorbance. CAT activity was measured at an excitation wavelength of $405 \mathrm{~nm}$ according to the method of Góth $^{(30)}$ using an assay kit. GSH-Px activity was measured at an excitation wavelength of $412 \mathrm{~nm}$ by quantifying the rate of oxidation of reduced glutathione (GSH) to form oxidised GSH. The thiobarbital method was used to determine cellular malondialdehyde concentration at an excitation wavelength of $532 \mathrm{~nm}$ by measuring the absorbance ${ }^{(31)}$. The cellular protein concentration was determined using the Coomassie Brilliant Blue G250 reagent, with bovine serum albumin used as a standard.

\section{Ig and cytokine assays}

The concentrations of Ig were measured by solid-phase indirect ELISA as described by Islam et $a l{ }^{(32)}$. The cellular concentrations of TNF- $\alpha$, IL- $1 \beta$, IL- 8 and Toll-like receptor 4 (TLR4) were determined using bovine-specific commercial ELISA kits for TNF- $\alpha$ (E90133Bo; Uscn Life Science Inc.), IL-1 $\beta$ (E90563Bo; Uscn Life Science Inc.), IL-8 (E90080Bo; Uscn Life Science Inc.) and TLR4 (A90753Bo01; Uscn Life Science Inc.), respectively.

Total RNA was isolated from the cultured cells according to the manufacturer's instructions. First-strand complementary DNA was synthesised using the RevertAid ${ }^{\mathrm{TM}}$ First Strand cDNA Synthesis Kit (K1622; Fermentas Inc.). To quantify the mRNA of glyceraldehyde 3-phosphate dehydrogenase (GAPDH, a housekeeping gene) ${ }^{(33)}, I L-1 \beta, I L-8, T L R 4, T N F-\alpha$, epidermal growth factor $(E G F)$ and EGF receptor $(E G F R)$, real-time PCR was carried out using the complementary DNA of JEC. Primer sequences for each gene are listed in Table 1. The specificity of the primers was tested with a BLAST analysis against the genomic NCBI database. Real-time PCR was carried out using the SYBR Green method and the ABI 7900 Sequence Detection System (Applied Biosystems). Analyses were carried out in triplicate, and mean values were calculated. Data were collected and analysed using the 'fit point' option of the LightCycler software (version 3.5; Idaho Technology Inc.). A calibration curve was generated by the amplification of serially diluted complementary DNA using the fit point option of the LightCycler software for the target genes and GAPDH gene as an internal reference. The threshold fluorescence level was determined within the geometric region of the semi-log view of the amplification plot. The relative expression of the target gene was calculated using the $2^{-\Delta \Delta C_{\mathrm{t}}} \operatorname{method}^{(34)}$.

\section{Immunoblotting analysis}

The cells were lysed on ice for $30 \mathrm{~min}$ in a radioimmunoprecipitation assay buffer (150 mM-NaCl, 50 mm-Tris-HCl, pH 8.0, $1 \%$ Triton X-100, $1 \%$ sodium deoxycholate and $0 \cdot 1 \%$ SDS) containing a protease inhibitor cocktail (1:1000 dilution; Sigma-Aldrich). Lysates were collected, passed through a $21 \mathrm{G}$ needle and centrifuged $\left(14000 \mathrm{~g}\right.$ for $15 \mathrm{~min}$ at $4^{\circ} \mathrm{C}$ ) to remove particulate matter. Protein content in the lysate supernatants was determined using DC Protein Assay reagents (Bio-Rad Laboratories) and bovine serum albumin as a standard. Equal quantities of protein $(25 \mu \mathrm{g})$ were resolved using SDS-PAGE and transferred onto nitrocellulose membranes using semi-dry blotting techniques (Bio-Rad Laboratories). Non-specific protein-binding sites were blocked by treating the membranes with 5\% bovine serum albumin dissolved in Tris-buffered saline (10 mm-Tris- $\mathrm{HCl}, \mathrm{pH} 8 \cdot 0$, and $150 \mathrm{~mm}-\mathrm{NaCl})$ with $0.05 \%$ Tween-20. The membranes were incubated with primary anti-heat shock protein 70 (HSP70; no. 4825; Cell Signaling Technology, Inc.) and anti-GAPDH (no. GTX43800; Cell Signaling Technology, Inc.) antibodies, as well as horseradish peroxidase-conjugated secondary antibodies, in Tris-buffered saline with $0.05 \%$ Tween-20 and $1 \%$ bovine serum albumin. The bands were visualised using a chemiluminescence substrate (SuperSignal West Pico; Thermo Fisher Scientific) and fluorography. Densitometric analysis of the bands was carried out using an AlphaImager 2200 system (AlphaInnotech).

\section{Statistical analyses}

All statistical analyses were conducted using the generalised linear model procedure (SAS Institute, Inc.). The normality

Table 1. Primer sequences for genes in the jejunum mucosa

\begin{tabular}{|c|c|c|c|}
\hline & Primer sequence & $\begin{array}{l}\text { Length of the } \\
\text { PCR product (bp) }\end{array}$ & $T_{\mathrm{m}}\left({ }^{\circ} \mathrm{C}\right)$ \\
\hline \multirow[t]{2}{*}{ GAPDH } & Sense: $5^{\prime}$-GGTCACCAGGGCTGCTTT-3' & 128 & $57 \cdot 8$ \\
\hline & Antisense: $5^{\prime}$-CTGTGCCGTTGAACTTGC-3' & & $55 \cdot 0$ \\
\hline \multirow[t]{2}{*}{$I L-1 \beta$} & Sense: $5^{\prime}$-CCTGAACCCATCAACGAA-3' & 194 & $54 \cdot 1$ \\
\hline & Antisense: $5^{\prime}$-ACGATGACCGACACCACC-3' & & $56 \cdot 0$ \\
\hline \multirow[t]{2}{*}{ IL-8 } & Sense: 5'-GACTTCCAAGCTGGCTGTT-3' & 230 & $54 \cdot 9$ \\
\hline & Antisense: $5^{\prime}$-GGCAGACCTCGTTTCCAT-3' & & $55 \cdot 0$ \\
\hline \multirow[t]{2}{*}{ TLR4 } & Sense: $5^{\prime}$-CCTTCACTACAGGGACTT- $3^{\prime}$ & 96 & $45 \cdot 9$ \\
\hline & Antisense: $5^{\prime}$-GACACCACGACAATAACC- $3^{\prime}$ & & $47 \cdot 5$ \\
\hline \multirow[t]{2}{*}{$T N F-\alpha$} & Sense: $5^{\prime}$-CCCTTGTTCCTCACCCAC- $3^{\prime}$ & 250 & $55 \cdot 0$ \\
\hline & Antisense: 5'-CGATGATCCCAAAGTAGACC-3' & & $54 \cdot 3$ \\
\hline \multirow[t]{2}{*}{ EGF } & Sense: 5'-CGAGGAAGAAGTAGGTTTA-3' & 228 & $47 \cdot 0$ \\
\hline & Antisense: $5^{\prime}$-GAACTTTCAATTCGTGGA-3' & & 47.9 \\
\hline \multirow[t]{2}{*}{$E G F R$} & Sense: $5^{\prime}$-CACTCATGCTCTATGACCCTA-3' & 233 & $52 \cdot 6$ \\
\hline & Antisense: $5^{\prime}$-ACCGATTCCTATTCCGTTA-3' & & $53 \cdot 3$ \\
\hline
\end{tabular}

GAPDH, glyceraldehyde 3-phosphate dehydrogenase; TLR4, Toll-like receptor 4; EGF, epidermal growth factor; EGFR, epidermal growth factor receptor. 
of data distribution was assessed using the KolmogorovSmirnov goodness-of-fit test. As the experiments were organised in a $5 \times 4$ factorial design, a two-way ANOVA was used to test the effects of GSE concentration, temperature and temperature $\times$ GSE concentration interactions, followed by a Tukey's post hoc test. Orthogonal contrasts were used to examine the linear and quadratic effects in response to increasing temperature or GSE concentration. All statistical tests were two-sided and statistical significance was set at $P<0 \cdot 05$.

\section{Results}

Supplementation with 20,40 and $80 \mu \mathrm{g} / \mathrm{ml}$ GSE increased the GSH-Px activity of JEC cultured at $40^{\circ} \mathrm{C}(P=0.04)$ and the CAT activity of JEC cultured at $43^{\circ} \mathrm{C}(P=0.04$; Table 2$)$. On the whole, the activities of SOD (linear and quadratic, $P<0 \cdot 001$ ), CAT (linear and quadratic, $P<0.001$ ) and GSH-Px (linear, $P<0.001$; cubic, $P=0.02$ ) of JEC declined in response to an increase in culture temperature. A rise in culture temperature increased the malondialdehyde concentration of JEC (linear and quadratic, $P<0 \cdot 001$; cubic, $P=0 \cdot 01$ ). Supplementation of the culture medium with GSE increased the activities of SOD (linear, $P=0.04$ ), CAT (linear and quadratic, $P<0.001$ ) and GSH-Px (linear, $P=0 \cdot 01$ ) of JEC.
When cultured at $40^{\circ} \mathrm{C}, \mathrm{JEC}$ supplemented with 20,40 and $80 \mu \mathrm{g} / \mathrm{ml}$ GSE exhibited IL-1 $\beta(P=0.02)$ and TLR4 $(P=0.04)$ concentrations that were significantly higher than those in cells not supplemented with GSE (Table 3). When cultured at $43^{\circ} \mathrm{C}$, JEC supplemented with 20, 40 and $80 \mu \mathrm{g} / \mathrm{ml}$ GSE exhibited TLR $4(P=0.03)$ and TNF- $\alpha(P=0 \cdot 002)$ concentrations that were significantly lower than those in cells not supplemented with GSE. Overall, an increase was observed in the concentrations of IL-1 $\beta$ (linear and quadratic, $P<0 \cdot 001$; cubic, $P=0.003$ ), IL-8 (linear and quadratic, $P<0.001$; cubic, $P=0.02$ ), TLR4 (linear and quadratic, $P<0.001$ ) and TNF- $\alpha$ (linear, quadratic and cubic, $P<0.001)$ of JEC in response to an increase in culture temperature $(P<0 \cdot 001)$. Supplementation of the culture medium with GSE decreased the concentrations of IL-1 $\beta$ (linear and quadratic, $P<0.001$ ), IL- 8 (linear and quadratic, $P<0.001$ ), TLR4 (quadratic, $P=0.008$; cubic, $P=0.002$ ) and TNF- $\alpha$ (linear, $P=0.03$ ) of JEC. Significant temperature $\times$ GSE interactions were observed for the concentrations of IL-1 $\beta \quad(P<0.001)$, IL-8 $(P<0.001)$ and TNF- $\alpha$ $(P=0 \cdot 01)$ of cultured JEC.

When cultured at $40^{\circ} \mathrm{C}$, JEC supplemented with 40 and $80 \mu \mathrm{g} / \mathrm{ml}$ GSE exhibited decreased mRNA expression of $I L-8(P=0.01)$ and $T N F-\alpha(P=0.03)$ and increased mRNA expression of $E G F(P=0.03)$ when compared with those not

Table 2. Effects of grape seed extract (GSE) and heat stress on the antioxidant capacity of jejunum epithelial cells of a Simmental $\times$ Qinchuan steer

(Mean values and standard deviations; $n$ )

\begin{tabular}{|c|c|c|c|c|c|c|c|c|c|}
\hline & & \multicolumn{2}{|c|}{$\begin{array}{c}\text { SOD } \\
\text { (1000 IU/g protein) }\end{array}$} & \multicolumn{2}{|c|}{$\begin{array}{c}\text { CAT } \\
\text { (1000 IU/g protein) }\end{array}$} & \multicolumn{2}{|c|}{$\begin{array}{c}\text { GSH-Px } \\
\text { (1000 IU/g protein) }\end{array}$} & \multicolumn{2}{|c|}{$\begin{array}{c}\text { MDA } \\
(\mu \mathrm{mol} / \mathrm{g} \text { protein) }\end{array}$} \\
\hline & & Mean & SD & Mean & SD & Mean & SD & Mean & SD \\
\hline \multirow[t]{5}{*}{$37^{\circ} \mathrm{C}$} & $0 \mu \mathrm{g} / \mathrm{ml}$ & 227 & 9.03 & 4.46 & 0.17 & 129 & $5 \cdot 11$ & 1.80 & 0.14 \\
\hline & $10 \mu \mathrm{g} / \mathrm{ml}$ & 228 & $26 \cdot 1$ & 4.53 & 0.19 & 123 & $5 \cdot 38$ & 1.72 & 0.19 \\
\hline & $20 \mu \mathrm{g} / \mathrm{ml}$ & 221 & 10.5 & 4.64 & 0.20 & 125 & $9 \cdot 33$ & 1.77 & 0.23 \\
\hline & $40 \mu \mathrm{g} / \mathrm{ml}$ & 230 & $6 \cdot 28$ & $4 \cdot 73$ & 0.28 & 130 & 5.95 & 1.80 & 0.11 \\
\hline & $80 \mu \mathrm{g} / \mathrm{ml}$ & 232 & $7 \cdot 14$ & 4.71 & $0 \cdot 10$ & 128 & $6 \cdot 65$ & 1.83 & 0.11 \\
\hline \multirow{5}{*}{$40^{\circ} \mathrm{C}$} & $0 \mu \mathrm{g} / \mathrm{ml}$ & 201 & 8.04 & 3.95 & 0.25 & $103^{b}$ & $4 \cdot 71$ & 2.02 & 0.19 \\
\hline & $10 \mu \mathrm{g} / \mathrm{ml}$ & 213 & $11 \cdot 1$ & 4.28 & 0.49 & $109^{a, b}$ & 8.35 & 2.08 & 0.28 \\
\hline & $20 \mu \mathrm{g} / \mathrm{ml}$ & 215 & 5.92 & 4.40 & 0.28 & $115^{\mathrm{a}}$ & 5.42 & 2.02 & 0.31 \\
\hline & $40 \mu \mathrm{g} / \mathrm{ml}$ & 218 & 20.6 & 4.49 & 0.47 & $115^{\mathrm{a}}$ & 11.4 & 1.95 & 0.52 \\
\hline & $80 \mu \mathrm{g} / \mathrm{ml}$ & 216 & 6.68 & 4.50 & 0.09 & $116^{\mathrm{a}}$ & 5.59 & 1.97 & 0.47 \\
\hline \multirow[t]{5}{*}{$43^{\circ} \mathrm{C}$} & $0 \mu \mathrm{g} / \mathrm{ml}$ & 180 & $7 \cdot 13$ & $3.36^{\mathrm{b}}$ & 0.15 & 99.8 & $5 \cdot 60$ & $2 \cdot 19$ & 0.14 \\
\hline & $10 \mu \mathrm{g} / \mathrm{ml}$ & 185 & $21 \cdot 2$ & $3.67^{a, b}$ & 0.16 & $99 \cdot 4$ & $4 \cdot 36$ & 2.06 & 0.48 \\
\hline & $20 \mu \mathrm{g} / \mathrm{ml}$ & 191 & $15 \cdot 9$ & $3 \cdot 84^{\mathrm{a}}$ & 0.23 & 104 & $15 \cdot 0$ & 2.02 & 0.33 \\
\hline & $40 \mu \mathrm{g} / \mathrm{ml}$ & 185 & 17.5 & $3.81^{a}$ & 0.40 & 105 & $10 \cdot 9$ & 1.91 & 0.51 \\
\hline & $80 \mu \mathrm{g} / \mathrm{ml}$ & 187 & 4.64 & $3 \cdot 81^{a}$ & 0.12 & 103 & 5.91 & 2.42 & 0.07 \\
\hline \multirow{5}{*}{$46^{\circ} \mathrm{C}$} & $0 \mu \mathrm{g} / \mathrm{ml}$ & 144 & 6.44 & 2.93 & 0.14 & $81 \cdot 8$ & $5 \cdot 96$ & 2.83 & 0.14 \\
\hline & $10 \mu \mathrm{g} / \mathrm{ml}$ & 146 & 13.8 & 2.90 & 0.23 & $78 \cdot 6$ & 5.95 & $2 \cdot 81$ & 0.13 \\
\hline & $20 \mu \mathrm{g} / \mathrm{ml}$ & 150 & $8 \cdot 21$ & $3 \cdot 10$ & $0 \cdot 16$ & 84.5 & 5.94 & $2 \cdot 76$ & $0 \cdot 12$ \\
\hline & $40 \mu \mathrm{g} / \mathrm{ml}$ & 151 & $4 \cdot 13$ & 3.07 & 0.19 & 85.5 & 3.91 & 2.74 & $0 \cdot 16$ \\
\hline & $80 \mu \mathrm{g} / \mathrm{ml}$ & 152 & 4.69 & 3.04 & 0.06 & $85 \cdot 1$ & 4.91 & 2.75 & 0.11 \\
\hline \multirow{4}{*}{$\begin{array}{l}\text { Pooled SEM } \\
\text { T }\end{array}$} & & \multicolumn{2}{|c|}{$5 \cdot 53$} & \multicolumn{2}{|c|}{0.11} & \multicolumn{2}{|c|}{$3 \cdot 28$} & \multicolumn{2}{|c|}{0.12} \\
\hline & Linear & \multirow{2}{*}{\multicolumn{2}{|c|}{$<0.001$}} & \multirow{2}{*}{\multicolumn{2}{|c|}{$\begin{array}{l}<0.001 \\
<0.001\end{array}$}} & \multicolumn{2}{|c|}{$<0.001$} & \multirow{2}{*}{\multicolumn{2}{|c|}{$<0.001$}} \\
\hline & Quadratic & & & & & \multirow{2}{*}{\multicolumn{2}{|c|}{$\begin{array}{l}0.17 \\
0.02\end{array}$}} & \multirow{2}{*}{\multicolumn{2}{|c|}{$\begin{array}{c}<0.001 \\
0.01\end{array}$}} \\
\hline & Cubic & \multicolumn{2}{|c|}{0.86} & \multicolumn{2}{|c|}{0.33} & & & & \\
\hline \multirow[t]{3}{*}{ GSE } & Linear & \multicolumn{2}{|c|}{0.04} & \multicolumn{2}{|c|}{$<0.001$} & \multicolumn{2}{|c|}{0.01} & \multicolumn{2}{|c|}{0.60} \\
\hline & Quadratic & \multicolumn{2}{|c|}{0.22} & \multirow{2}{*}{\multicolumn{2}{|c|}{$\begin{array}{c}<0.001 \\
0.14\end{array}$}} & \multirow{2}{*}{\multicolumn{2}{|c|}{0.06}} & & \\
\hline & Cubic & & & & & & & & \\
\hline $\mathrm{T} \times \mathrm{GSE}$ & & & & & & & & & \\
\hline
\end{tabular}

SOD, superoxide dismutase; CAT, catalase; GSH-Px, glutathione peroxidase; MDA, malondialdehyde; T, temperature; T $\times$ GSE, interaction between $\mathrm{T}$ and GSE.

a,b Mean values within a column with unlike superscript letters were significantly different $(P<0.05)$. 
Table 3. Effects of grape seed extract (GSE) and heat stress on the immune parameters of jejunum epithelial cells of a Simmental $\times$ Qinchuan steer

(Mean values and standard deviations; $n$ )

\begin{tabular}{|c|c|c|c|c|c|c|c|c|c|c|c|c|c|}
\hline & & \multicolumn{2}{|c|}{$\begin{array}{c}\text { IgM } \\
\text { (mg/g protein) }\end{array}$} & \multicolumn{2}{|c|}{$\begin{array}{c}\text { IgG } \\
\text { (mg/g protein) }\end{array}$} & \multicolumn{2}{|c|}{$\begin{array}{c}\mathrm{IL}-1 \beta \\
\text { (ng/g protein) }\end{array}$} & \multicolumn{2}{|c|}{$\begin{array}{c}\text { IL-8 } \\
\text { (ng/g protein) }\end{array}$} & \multicolumn{2}{|c|}{$\begin{array}{c}\text { TLR4 } \\
\text { (ng/g protein) }\end{array}$} & \multicolumn{2}{|c|}{$\begin{array}{c}\text { TNF- } \alpha \\
\text { (ng/g protein) }\end{array}$} \\
\hline & & Mean & SD & Mean & SD & Mean & SD & Mean & SD & Mean & SD & Mean & SD \\
\hline \multirow[t]{5}{*}{$37^{\circ} \mathrm{C}$} & $0 \mu \mathrm{g} / \mathrm{ml}$ & $2 \cdot 62$ & 0.45 & $42 \cdot 5$ & 5.06 & 0.36 & 0.02 & 0.21 & 0.03 & 0.47 & 0.03 & 0.48 & 0.02 \\
\hline & $10 \mu \mathrm{g} / \mathrm{ml}$ & 2.43 & 0.31 & $43 \cdot 6$ & 3.41 & 0.34 & 0.05 & 0.20 & 0.05 & 0.47 & 0.02 & 0.49 & 0.05 \\
\hline & $20 \mu \mathrm{g} / \mathrm{ml}$ & 2.51 & 0.41 & 41.4 & 3.63 & 0.35 & 0.04 & 0.22 & 0.04 & 0.46 & 0.02 & 0.50 & 0.03 \\
\hline & $40 \mu \mathrm{g} / \mathrm{ml}$ & 2.77 & 0.16 & $41 \cdot 7$ & 3.87 & 0.34 & 0.02 & 0.21 & 0.02 & 0.49 & 0.03 & 0.48 & 0.03 \\
\hline & $80 \mu \mathrm{g} / \mathrm{ml}$ & 2.59 & 0.28 & $40 \cdot 6$ & $4 \cdot 13$ & 0.34 & 0.03 & 0.22 & 0.03 & 0.50 & 0.02 & 0.51 & 0.02 \\
\hline \multirow[t]{5}{*}{$40^{\circ} \mathrm{C}$} & $0 \mu \mathrm{g} / \mathrm{ml}$ & $2 \cdot 80$ & 0.41 & $62 \cdot 1^{\mathrm{a}}$ & $3 \cdot 82$ & $0.45^{\mathrm{a}}$ & 0.03 & $0.32^{a}$ & 0.03 & $0.66^{a}$ & 0.04 & 0.63 & 0.05 \\
\hline & $10 \mu \mathrm{g} / \mathrm{ml}$ & $3 \cdot 18$ & 0.49 & $57 \cdot 3^{a, b}$ & 5.97 & $0 \cdot 39^{a, b}$ & 0.03 & $0.27^{\mathrm{b}}$ & 0.02 & $0.60^{a, b}$ & 0.05 & 0.62 & 0.07 \\
\hline & $20 \mu \mathrm{g} / \mathrm{ml}$ & $3 \cdot 15$ & 0.42 & $54 \cdot 1^{\mathrm{b}}$ & 4.07 & $0 \cdot 37^{b}$ & 0.08 & $0.26^{b}$ & 0.02 & $0.55^{\mathrm{b}}$ & 0.04 & 0.64 & 0.05 \\
\hline & $40 \mu \mathrm{g} / \mathrm{ml}$ & 3.00 & 0.41 & $52 \cdot 2^{b}$ & $4 \cdot 22$ & $0.34^{b}$ & 0.06 & $0.24^{b}$ & 0.03 & $0.58^{b}$ & 0.05 & 0.62 & 0.06 \\
\hline & $80 \mu \mathrm{g} / \mathrm{ml}$ & 2.79 & 0.40 & $51.9^{b}$ & $6 \cdot 22$ & $0.36^{b}$ & 0.04 & $0.25^{\mathrm{b}}$ & 0.02 & $0.58^{\mathrm{b}}$ & 0.04 & 0.62 & 0.02 \\
\hline \multirow[t]{5}{*}{$43^{\circ} \mathrm{C}$} & $0 \mu \mathrm{g} / \mathrm{ml}$ & $2 \cdot 88^{a}$ & 0.24 & $72 \cdot 3$ & $9 \cdot 85$ & $0.51^{a}$ & 0.03 & $0 \cdot 41^{a}$ & 0.03 & $0 \cdot 81^{a}$ & 0.06 & $0.86^{a}$ & 0.07 \\
\hline & $10 \mu \mathrm{g} / \mathrm{ml}$ & $2 \cdot 82^{a, b}$ & 0.06 & $70 \cdot 4$ & $5 \cdot 88$ & $0.45^{\mathrm{b}}$ & 0.03 & $0.37^{\mathrm{b}}$ & 0.03 & $0.76^{a, b}$ & 0.04 & $0.83^{a, b}$ & 0.05 \\
\hline & $20 \mu \mathrm{g} / \mathrm{ml}$ & $2 \cdot 70^{b, c}$ & 0.10 & $67 \cdot 6$ & $4 \cdot 26$ & $0 \cdot 39^{c}$ & 0.03 & $0.32^{\mathrm{c}}$ & 0.03 & $0 \cdot 70^{\mathrm{b}}$ & 0.06 & $0.78^{b, c}$ & 0.05 \\
\hline & $40 \mu \mathrm{g} / \mathrm{ml}$ & $2 \cdot 65^{\mathrm{b}, \mathrm{c}}$ & 0.08 & $67 \cdot 4$ & 7.02 & $0 \cdot 36^{c}$ & 0.05 & $0.30^{c}$ & 0.03 & $0.71^{b}$ & 0.06 & $0.73^{c}$ & 0.07 \\
\hline & $80 \mu \mathrm{g} / \mathrm{ml}$ & $2 \cdot 63^{c}$ & 0.09 & $65 \cdot 5$ & $6 \cdot 76$ & $0 \cdot 35^{c}$ & 0.04 & $0.30^{c}$ & 0.01 & $0.71^{b}$ & 0.06 & $0.72^{c}$ & 0.02 \\
\hline \multirow[t]{5}{*}{$46^{\circ} \mathrm{C}$} & $0 \mu \mathrm{g} / \mathrm{ml}$ & 3.59 & 0.48 & 81.4 & $7 \cdot 43$ & 0.55 & 0.01 & 0.49 & 0.04 & 1.02 & 0.06 & $1 \cdot 39$ & 0.07 \\
\hline & $10 \mu \mathrm{g} / \mathrm{ml}$ & 3.56 & 0.46 & $78 \cdot 1$ & 4.89 & 0.53 & 0.04 & 0.50 & 0.03 & 0.97 & 0.06 & $1 \cdot 36$ & 0.09 \\
\hline & $20 \mu \mathrm{g} / \mathrm{ml}$ & 3.49 & 0.45 & $79 \cdot 6$ & $5 \cdot 00$ & 0.54 & 0.05 & 0.48 & 0.04 & 0.95 & 0.06 & $1 \cdot 34$ & 0.08 \\
\hline & $40 \mu \mathrm{g} / \mathrm{ml}$ & 3.45 & 0.47 & $81 \cdot 1$ & $6 \cdot 25$ & 0.55 & 0.03 & 0.49 & 0.04 & 1.00 & 0.06 & $1 \cdot 37$ & 0.06 \\
\hline & $80 \mu \mathrm{g} / \mathrm{ml}$ & 3.48 & 0.44 & $80 \cdot 8$ & $9 \cdot 46$ & 0.54 & 0.03 & 0.49 & 0.05 & 1.01 & 0.06 & $1 \cdot 37$ & 0.07 \\
\hline Pooled SEM & & \multicolumn{2}{|c|}{0.19} & \multicolumn{2}{|c|}{1.85} & \multicolumn{2}{|c|}{0.02} & \multicolumn{2}{|c|}{0.01} & \multicolumn{2}{|c|}{0.02} & \multicolumn{2}{|c|}{0.02} \\
\hline \multirow{3}{*}{$\mathrm{T}$} & Linear & \multicolumn{2}{|c|}{$<0.001$} & \multicolumn{2}{|c|}{$<0.001$} & \multicolumn{2}{|c|}{$<0.001$} & \multicolumn{2}{|c|}{$<0.001$} & \multicolumn{2}{|c|}{$<0.001$} & \multicolumn{2}{|c|}{$<0.001$} \\
\hline & Quadratic & \multicolumn{2}{|c|}{0.03} & \multicolumn{2}{|c|}{0.23} & \multicolumn{2}{|c|}{$<0.001$} & \multicolumn{2}{|c|}{$<0.001$} & $<0$ & & $<0$ & \\
\hline & Cubic & $<0$. & & & & & & & & 0 & & $<0$ & \\
\hline GSE & Linear & & & & & $<0$ & & $<0$ & & 0 & & & \\
\hline & Quadratic & & & & & $<0$. & & $<0$ & & & & & \\
\hline & Cubic & & & & & 0 & & & & & & & \\
\hline $\mathrm{T} \times \mathrm{GSE}$ & & & & & & $<0$. & & $<0$ & & 0. & & & \\
\hline
\end{tabular}

TLR4, Toll-like receptor 4; T, temperature; $T \times$ GSE, interaction between $T$ and GSE.

a,b,c Mean values within a column with unlike superscript letters were significantly different $(P<0.05)$.

supplemented with GSE (Table 4). When cultured at $43^{\circ} \mathrm{C}$, JEC supplemented with 20,40 and $80 \mu \mathrm{g} / \mathrm{ml}$ GSE exhibited mRNA expression of $I L-8(P<0.001)$ and TLR4 $(P=0.002)$ that was lower than that in cells not supplemented with GSE. On the whole, increases were observed in the mRNA expression of $I L-1 \beta$ (linear, $P<0.001$; quadratic and cubic, $P=0 \cdot 002$ ), $I L-8$, TLR4 and TNF- $\alpha$ (linear, quadratic and cubic, $P<0.001$ ) of JEC in response to an increase in culture temperature and declines were observed in the mRNA expression of $E G F$ (linear, quadratic and cubic, $P<0.001$ ) and $E G F R$ (linear and cubic, $P<0 \cdot 001)$. Supplementation of the culture medium with GSE decreased the mRNA expression of $I L-8$ and $T N F-\alpha$ (linear, $P=0.002$ ) and increased the mRNA expression of $E G F$ and EGFR (linear, $P<0.001$ ) of JEC.

When cultured at $40^{\circ} \mathrm{C}$, JEC supplemented with 40 and $80 \mu \mathrm{g} / \mathrm{ml}$ GSE exhibited viability that was greater than that of cells supplemented with 0 and $10 \mu \mathrm{g} / \mathrm{ml}$ GSE $(P=0.004)$ and those supplemented with 0 and $10 \mu \mathrm{g} / \mathrm{ml}$ GSE exhibited HSP70 concentration that was greater than that of cells supplemented with 40 and $80 \mu \mathrm{g} / \mathrm{ml}$ GSE $(P<0 \cdot 001$; Table 5). Similarly, when cultured at $43^{\circ} \mathrm{C}$, JEC supplemented with 20 , 40 and $80 \mu \mathrm{g} / \mathrm{ml}$ GSE exhibited viability that was greater than that of cells supplemented with 0 and $10 \mu \mathrm{g} / \mathrm{ml} \mathrm{GSE}$ $(P<0.001)$ and those supplemented with 0 and $10 \mu \mathrm{g} / \mathrm{ml}$ GSE exhibited HSP70 concentration that was greater than that of cells supplemented with 20, 40 and $80 \mu \mathrm{g} / \mathrm{ml}$
$(P<0 \cdot 001)$. Overall, the viability of JEC declined in response to an increase in culture temperature (linear and cubic, $P<0.001)$, whereas the concentration of HSP70 increased (linear, quadratic and cubic, $P<0 \cdot 001$ ). Supplementation of the culture medium with GSE increased the viability of JEC (linear, $P<0.001$; quadratic, $P=0.002$ ) and decreased the concentration of HSP70 (linear and quadratic, $P<0.001$ ). Temperature $\times$ GSE interactions were detected for cell viability $(P<0 \cdot 001)$ and HSP70 concentration of JEC $(P=0 \cdot 004)$.

\section{Discussion}

The biological properties of polyphenols are dependent on the quantity of polyphenols consumed and on their bioavailability, which apparently differs greatly among the various polyphenols $^{(35)}$. Most polyphenols present in food exist in the form of esters, glycosides or polymers that cannot be absorbed in their native form. Typically, these substances must be cleaved before absorption ${ }^{(36,37)}$. Polyphenols with relatively small molecular weights are easily absorbed through the gut ${ }^{(38)}$. Most of the absorbed polyphenols present in the circulation and tissues predominately exist in conjugated forms - glucuronised, sulphated or methylated - or in a combination of these forms ${ }^{(39)}$. We speculate that the bioavailability of polyphenols in the GSE used in the present study would be high because it contains a relatively high proportion 
Table 4. Effects of grape seed extract (GSE) and heat stress on the mRNA expression of cytokines of jejunum epithelial cells of a Simmental $\times$ Qinchuan steer

(Mean values and standard deviations; $n 4$ )

\begin{tabular}{|c|c|c|c|c|c|c|c|c|c|c|c|c|c|}
\hline & & \multicolumn{2}{|c|}{$I L-1 \beta$} & \multicolumn{2}{|c|}{$I L-8$} & \multicolumn{2}{|c|}{ TLR4 } & \multicolumn{2}{|c|}{$T N F-\alpha$} & \multicolumn{2}{|c|}{$E G F$} & \multicolumn{2}{|c|}{$E G F R$} \\
\hline & & Mean & SD & Mean & SD & Mean & SD & Mean & $\mathrm{SD}$ & Mean & SD & Mean & SD \\
\hline \multirow[t]{5}{*}{$37^{\circ} \mathrm{C}$} & $0 \mu \mathrm{g} / \mathrm{ml}$ & 1.00 & 0.12 & 1.00 & 0.08 & 1.00 & 0.07 & 1.00 & 0.06 & 1.00 & 0.05 & 1.00 & 0.05 \\
\hline & $10 \mu \mathrm{g} / \mathrm{ml}$ & 1.03 & $0 \cdot 10$ & 1.00 & 0.06 & 1.03 & 0.06 & 1.03 & 0.06 & 0.99 & 0.05 & 1.01 & 0.04 \\
\hline & $20 \mu \mathrm{g} / \mathrm{ml}$ & 1.04 & 0.25 & 1.03 & 0.01 & 0.97 & 0.05 & 0.97 & 0.05 & 0.97 & 0.05 & 1.03 & 0.01 \\
\hline & $40 \mu \mathrm{g} / \mathrm{ml}$ & 1.04 & 0.26 & 1.01 & 0.04 & 0.99 & 0.05 & 0.99 & 0.05 & 1.03 & 0.06 & 1.00 & 0.06 \\
\hline & $80 \mu \mathrm{g} / \mathrm{ml}$ & 0.98 & 0.17 & 1.00 & 0.05 & 0.98 & 0.05 & 0.98 & 0.05 & 1.00 & 0.04 & 1.00 & 0.05 \\
\hline \multirow[t]{5}{*}{$40^{\circ} \mathrm{C}$} & $0 \mu \mathrm{g} / \mathrm{ml}$ & 1.00 & 0.11 & $1.00^{\mathrm{a}}$ & 0.04 & 1.00 & 0.17 & $1.00^{\mathrm{a}}$ & 0.07 & $1.00^{\mathrm{b}}$ & 0.09 & $1.00^{b}$ & 0.07 \\
\hline & $10 \mu \mathrm{g} / \mathrm{ml}$ & 0.95 & 0.08 & $0.95^{\mathrm{a}, \mathrm{b}}$ & 0.06 & 0.96 & 0.01 & $0.97^{\mathrm{a}, \mathrm{b}}$ & 0.05 & $1 \cdot 00^{\mathrm{a}, \mathrm{b}}$ & 0.10 & $1.07^{b}$ & 0.18 \\
\hline & $20 \mu \mathrm{g} / \mathrm{ml}$ & 0.92 & 0.15 & $0.95^{\mathrm{a}, \mathrm{b}}$ & 0.04 & 0.93 & 0.05 & $0.95^{\mathrm{a}, \mathrm{b}}$ & 0.04 & $1.08^{\mathrm{a}, \mathrm{b}}$ & 0.02 & $1 \cdot 17^{\mathrm{a}, \mathrm{b}}$ & 0.07 \\
\hline & $40 \mu \mathrm{g} / \mathrm{ml}$ & 0.94 & 0.06 & $0.90^{\mathrm{b}, \mathrm{c}}$ & 0.09 & 0.88 & 0.05 & $0.91^{b}$ & 0.07 & $1.12^{\mathrm{a}}$ & 0.10 & $1 \cdot 18^{\mathrm{a}, \mathrm{b}}$ & 0.12 \\
\hline & $80 \mu \mathrm{g} / \mathrm{ml}$ & 0.94 & 0.07 & $0.86^{c}$ & 0.06 & 0.87 & 0.11 & $0.91^{\mathrm{b}}$ & 0.07 & $1 \cdot 18^{\mathrm{a}}$ & 0.10 & $1.23^{a}$ & 0.07 \\
\hline \multirow[t]{5}{*}{$43^{\circ} \mathrm{C}$} & $0 \mu \mathrm{g} / \mathrm{ml}$ & 1.00 & 0.04 & $1.00^{\mathrm{a}}$ & 0.05 & $1.00^{\mathrm{a}}$ & 0.05 & $1.00^{a}$ & 0.05 & $1.00^{\mathrm{b}}$ & 0.06 & $1.00^{c}$ & 0.02 \\
\hline & $10 \mu \mathrm{g} / \mathrm{ml}$ & 0.99 & 0.09 & $0.96^{\mathrm{a}, \mathrm{b}}$ & 0.04 & $0.98^{\mathrm{a}, \mathrm{b}}$ & 0.05 & $0.95^{\mathrm{b}}$ & 0.06 & $1.00^{\mathrm{b}}$ & 0.06 & $1.08^{\mathrm{c}}$ & 0.17 \\
\hline & $20 \mu \mathrm{g} / \mathrm{ml}$ & 0.94 & 0.05 & $0.92^{b, c}$ & 0.02 & $0.95^{\mathrm{b}, \mathrm{c}}$ & 0.07 & $0.93^{b}$ & 0.05 & $1 \cdot 13^{\mathrm{b}}$ & 0.10 & $1 \cdot 20^{\mathrm{b}, \mathrm{c}}$ & 0.07 \\
\hline & $40 \mu \mathrm{g} / \mathrm{ml}$ & 0.92 & 0.06 & $0.90^{c}$ & 0.05 & $0.93^{\mathrm{c}}$ & 0.04 & $0.90^{\mathrm{b}}$ & 0.06 & $1 \cdot 21^{b}$ & 0.08 & $1.45^{\mathrm{a}, \mathrm{b}}$ & 0.09 \\
\hline & $80 \mu \mathrm{g} / \mathrm{ml}$ & 0.91 & 0.03 & $0.89^{c}$ & 0.02 & $0.92^{c}$ & 0.05 & $0.90^{\mathrm{b}}$ & 0.06 & $1.46^{\mathrm{a}}$ & 0.07 & $1.73^{\mathrm{a}}$ & 0.12 \\
\hline \multirow[t]{5}{*}{$46^{\circ} \mathrm{C}$} & $0 \mu \mathrm{g} / \mathrm{ml}$ & 1.00 & 0.13 & 1.00 & 0.03 & 1.00 & 0.07 & 1.00 & 0.09 & 1.00 & 0.20 & 1.00 & 0.21 \\
\hline & $10 \mu \mathrm{g} / \mathrm{ml}$ & 0.97 & 0.07 & 0.99 & 0.11 & 0.99 & 0.20 & 1.01 & 0.05 & 1.02 & 0.18 & 0.98 & $0 \cdot 16$ \\
\hline & $20 \mu \mathrm{g} / \mathrm{ml}$ & 0.98 & 0.03 & 0.97 & 0.12 & 1.00 & 0.08 & 1.01 & 0.06 & 1.15 & 0.30 & 0.94 & 0.24 \\
\hline & $40 \mu \mathrm{g} / \mathrm{ml}$ & 0.96 & 0.07 & 0.98 & 0.10 & 0.99 & 0.05 & 0.99 & 0.06 & $1 \cdot 12$ & 0.18 & 1.06 & 0.21 \\
\hline & $80 \mu \mathrm{g} / \mathrm{ml}$ & 1.02 & 0.03 & 0.98 & 0.04 & 1.00 & 0.05 & 0.99 & 0.03 & $1 \cdot 12$ & 0.22 & 1.12 & 0.18 \\
\hline \multirow{4}{*}{$\begin{array}{l}\text { Pooled SEM } \\
\mathrm{T}\end{array}$} & & \multicolumn{2}{|c|}{0.07} & \multicolumn{2}{|c|}{0.06} & \multicolumn{2}{|c|}{0.11} & \multicolumn{2}{|c|}{0.04} & \multicolumn{2}{|c|}{0.04} & \multicolumn{2}{|c|}{0.05} \\
\hline & Linear & \multirow{2}{*}{\multicolumn{2}{|c|}{$\begin{array}{r}<0.001 \\
0.002\end{array}$}} & \multirow{2}{*}{\multicolumn{2}{|c|}{$\begin{array}{l}<0.001 \\
<0.001\end{array}$}} & \multirow{2}{*}{\multicolumn{2}{|c|}{$\begin{array}{l}<0.001 \\
<0.001\end{array}$}} & \multirow{2}{*}{\multicolumn{2}{|c|}{$<0.001$}} & \multirow{2}{*}{\multicolumn{2}{|c|}{$<0.001$}} & \multirow{2}{*}{\multicolumn{2}{|c|}{$<0.001$}} \\
\hline & Quadratic & & & & & & & & & & & & \\
\hline & Cubic & \multicolumn{2}{|c|}{0.002} & \multicolumn{2}{|c|}{$<0.001$} & \multicolumn{2}{|c|}{$\begin{array}{l}<0.001 \\
<0.001\end{array}$} & \multicolumn{2}{|c|}{$\begin{array}{l}<0.001 \\
<0.001\end{array}$} & $<0$ & & $<0$ & \\
\hline GSE & Linear & & & & & & & & & $<0$ & & $<0$ & \\
\hline & Quadratic & & & & & & & 0. & & & & & \\
\hline & Cubic & & & & & 0 & & 0. & & & & & \\
\hline $\mathrm{T} \times \mathrm{GSE}$ & & & & & & & & 0. & & & & & \\
\hline
\end{tabular}

TLR4, Toll-like receptor 4; EGF, epidermal growth factor; EGFR, epidermal growth factor receptor; T, temperature; T $\times$ GSE, interaction between T and GSE. ${ }_{\mathrm{a}, \mathrm{b}, \mathrm{c}}$ Mean values within a column with unlike superscript letters were significantly different $(P<0.05)$.

of monomeric or oligomeric polyphenols. However, data concerning differences in bioavailability between GSE polyphenols and dietary polyphenols are limited and therefore further study is required.

\section{Antioxidant capacity}

The antioxidation defence network of animal organs and tissues acting against oxygen-free radicals includes endogenous (e.g. SOD, GSH, GSH-Px and CAT) and exogenous (e.g. vitamin $\mathrm{E}$ and $\mathrm{Se}$ ) factors ${ }^{(40)}$. In the present study, the activities of SOD, CAT and GSH-Px of JEC declined in response to an increase in culture temperature, whereas the cellular malondialdehyde concentration increased. These results indicate that heat stress decreases the antioxidant capacity of JEC and are in agreement with previous findings. Burke et al. ${ }^{(41)}$ reported that heat stress decreases the activities of GSH reductase and GSH-Px of peripheral blood mononuclear cells of heifers. Heat stress has been found to enhance the formation of reactive oxygen species and disturb the balance between the production of free radicals and the antioxidant systems, ultimately leading to oxidative stress ${ }^{(42-46)}$. Mujahid et al. ${ }^{(47)}$ also reported that heat stress increases the generation of free radicals, possibly through the disruption of electron transport assemblies of the mitochondrial membrane. Moreover, heat stress has been shown to decrease intestinal blood flow and ultimately reduce the absorption of nutrients, including exogenous antioxidant nutrients ${ }^{(48)}$.

In the present study, the CAT activity of JEC cultured at $43^{\circ} \mathrm{C}$ and the GSH-Px activity of those cultured at $40^{\circ} \mathrm{C}$ increased with GSE supplementation. This result indicates that GSE can assist in the maintenance of redox balance in JEC cultured at 40 and $43^{\circ} \mathrm{C}$. Primarily notable for the bioactivity of its phenolic compounds, GSE and its antioxidative characteristicsincluding scavenging of free radicals, inhibition of lipid oxidation and reduction of hydroperoxide formation- have been widely investigated ${ }^{(49,50)}$. The highest antioxidant capacity in grapes has been found in seeds, followed by skin, whereas the flesh has been found to have the lowest antioxidant capacity ${ }^{(51)}$. Some clinical data have shown that procyanidin oligomers present in grape seeds are twenty times more potent than vitamin $\mathrm{C}$ and fifty times more potent than vitamin $\mathrm{E}$ as antioxidants ${ }^{(22)}$. The antioxidant activity of GSE has also been reported to improve the oxidative stability of a variety of biological samples - including cooked beef $^{(52)}$, rats ${ }^{(53)}$, turkey, and pork patties, and coldstored turkey meat ${ }^{(54-56)}$ - based on in vitro and in vivo studies. Many investigators have attempted to identify the phenolic compounds and chemical structure(s) that are primarily responsible for the antioxidant activity of grape extracts. Faria et al. ${ }^{(57)}$ observed that in five fractions with differing compositions of procyanidin polymers, the dimers displayed 
Table 5. Effects of grape seed extract (GSE) and heat stress on the cell viability and heat shock protein 70 (HSP70) concentration of jejunum epithelial cells of a Simmental $\times$ Qinchuan steer

(Mean values and standard deviations; $n 4$ )

\begin{tabular}{|c|c|c|c|c|c|}
\hline & & \multicolumn{2}{|c|}{ Cell viability (\%) } & \multicolumn{2}{|c|}{$\begin{array}{c}\text { HSP70 } \\
\text { (spot intensity) }\end{array}$} \\
\hline & & Mean & SD & Mean & SD \\
\hline \multirow[t]{5}{*}{$37^{\circ} \mathrm{C}$} & $0 \mu \mathrm{g} / \mathrm{ml}$ & 0.88 & 0.04 & 0.47 & 0.04 \\
\hline & $10 \mu \mathrm{g} / \mathrm{ml}$ & 0.88 & 0.06 & 0.45 & 0.03 \\
\hline & $20 \mu \mathrm{g} / \mathrm{ml}$ & 0.84 & 0.05 & 0.48 & 0.03 \\
\hline & $40 \mu \mathrm{g} / \mathrm{ml}$ & 0.90 & 0.06 & 0.47 & 0.04 \\
\hline & $80 \mu \mathrm{g} / \mathrm{ml}$ & 0.94 & 0.07 & 0.43 & 0.03 \\
\hline \multirow{5}{*}{$40^{\circ} \mathrm{C}$} & $0 \mu \mathrm{g} / \mathrm{ml}$ & $0.69^{b}$ & 0.04 & $0.68^{a}$ & 0.04 \\
\hline & $10 \mu \mathrm{g} / \mathrm{ml}$ & $0.71^{b}$ & 0.03 & $0.66^{\mathrm{a}}$ & 0.06 \\
\hline & $20 \mu \mathrm{g} / \mathrm{ml}$ & $0.76^{a, b}$ & 0.07 & $0.61^{a, b}$ & 0.02 \\
\hline & $40 \mu \mathrm{g} / \mathrm{ml}$ & $0.82^{a}$ & 0.04 & $0.56^{\mathrm{b}}$ & 0.05 \\
\hline & $80 \mu \mathrm{g} / \mathrm{ml}$ & $0.84^{a}$ & 0.06 & $0.57^{\mathrm{b}}$ & 0.02 \\
\hline \multirow[t]{5}{*}{$43^{\circ} \mathrm{C}$} & $0 \mu \mathrm{g} / \mathrm{ml}$ & $0.64^{b}$ & 0.04 & $0.68^{\mathrm{a}}$ & 0.02 \\
\hline & $10 \mu \mathrm{g} / \mathrm{ml}$ & $0.66^{\mathrm{b}}$ & 0.06 & $0.67^{\mathrm{a}}$ & 0.03 \\
\hline & $20 \mu \mathrm{g} / \mathrm{ml}$ & $0.74^{a}$ & 0.05 & $0.61^{b}$ & 0.03 \\
\hline & $40 \mu \mathrm{g} / \mathrm{ml}$ & $0.76^{a}$ & 0.07 & $0.60^{\mathrm{b}}$ & 0.07 \\
\hline & $80 \mu \mathrm{g} / \mathrm{ml}$ & $0.77^{a}$ & 0.06 & $0.58^{\mathrm{b}}$ & 0.07 \\
\hline \multirow[t]{5}{*}{$46^{\circ} \mathrm{C}$} & $0 \mu \mathrm{g} / \mathrm{ml}$ & 0.54 & 0.03 & 0.72 & 0.02 \\
\hline & $10 \mu \mathrm{g} / \mathrm{ml}$ & 0.57 & 0.05 & 0.69 & 0.03 \\
\hline & $20 \mu \mathrm{g} / \mathrm{ml}$ & 0.60 & 0.05 & $0 \cdot 70$ & 0.03 \\
\hline & $40 \mu \mathrm{g} / \mathrm{ml}$ & 0.59 & 0.03 & 0.71 & 0.03 \\
\hline & $80 \mu \mathrm{g} / \mathrm{ml}$ & 0.62 & 0.05 & 0.68 & 0.04 \\
\hline \multicolumn{2}{|l|}{ Pooled SEM } & \multicolumn{2}{|c|}{0.02} & \multicolumn{2}{|c|}{0.01} \\
\hline \multirow[t]{3}{*}{$\mathrm{T}$} & Linear & \multicolumn{2}{|c|}{$<0.001$} & \multicolumn{2}{|c|}{$<0.001$} \\
\hline & Quadratic & \multicolumn{2}{|c|}{0.63} & \multicolumn{2}{|c|}{$<0.001$} \\
\hline & Cubic & \multicolumn{2}{|c|}{$<0.001$} & \multicolumn{2}{|c|}{$<0.001$} \\
\hline \multirow{3}{*}{ GSE } & Linear & \multicolumn{2}{|c|}{$<0.001$} & \multicolumn{2}{|c|}{$<0.001$} \\
\hline & Quadratic & \multicolumn{2}{|c|}{0.002} & \multicolumn{2}{|c|}{$<0.001$} \\
\hline & Cubic & \multirow{2}{*}{\multicolumn{2}{|c|}{0.30}} & \multirow{2}{*}{\multicolumn{2}{|c|}{$\begin{array}{l}0.78 \\
0.004\end{array}$}} \\
\hline $\mathrm{T} \times \mathrm{GSE}$ & & & & & \\
\hline
\end{tabular}

T, Temperature; $\mathrm{T} \times \mathrm{GSE}$, interaction between $\mathrm{T}$ and GSE.

${ }^{a, b}$ Mean values within a column with unlike superscript letters were significantly different $(P<0.05)$.

the highest antioxidant capacity based on a molar base (scavenging peroxyl radicals). A similar result was observed by Soobrattee et al. ${ }^{(58)}$, who reported that the compound with the highest antioxidative activity among the variety of phenolic compounds was the procyanidin dimer and that antioxidant capacity decreased in the order of procyanidin dimer $>$ flavanol $>$ flavonol $>$ hydroxycinnamic acids $>$ simple phenolic acids. Diphenols are more effective antioxidants than simpler phenols due to the stabilisation of the phenoxy radical through hydrogen bonding ${ }^{(59)}$. The high-molecular-weight compounds may be functionally as important as the monomer flavanols, such as catechin, which have been found to display high antioxidant potential among the phenolic compounds ${ }^{(23)}$. Furthermore, the antioxidant activity of a sample could be a function of a synergic effect among several components rather than of a single compound ${ }^{(60,61)}$.

\section{Immunity}

In the present study, the protein concentrations of IgG, IL-1 $\beta$, IL-8, TLR 4 and TNF- $\alpha$ and the mRNA expression levels of $I L-1 \beta, I L-8, T L R 4$ and $T N F-\alpha$ in JEC increased in response to an increase in culture temperature. As an important component of the immune system ${ }^{(6-8)}$, the gastrointestinal tract initiates protective immune responses induced upon encountering pathogens and toxins or tolerance to commensal bacteria and food antigens. Under normal health conditions, $\mathrm{T}$ cells appear to be activated but unstimulated (secreting cytokines), but are prepared for stimulation and to secrete a variety of cytokines, including IL-2, IL-4, IL-5, IL-10 and interferon- $\gamma^{(62)}$. Once invaded, the intestinal epithelium can function as a component of the innate immune system by expressing TLR (e.g. TLR2, TLR3, TLR4 and TLR5) and secrete cytokines (e.g. TNF- $\alpha$, IL-15 and IL-8) ${ }^{(63-66)}$. High circulating concentrations of cytokines in the plasma - including IL-1 $\beta$, IL-6 and IL-10 - have also been observed in heat strokeaffected animals and humans ${ }^{(67,68)}$. Heat shock has been shown to induce (in cultured intestinal epithelial cells) the production of cytokines (e.g. IL-6 and IL-8) ${ }^{(69)}$, directly resulting in increased epithelial permeability and a high rate of apoptosis ${ }^{(70)}$. Such a heightened immune response could result in a systemic inflammatory reaction, ultimately leading to multiple-organ failure, such as that observed during sepsis ${ }^{(9)}$.

In the present study, GSE supplementation was found to decrease the protein concentrations of IgG, IL-1 $\beta$, IL-8, TLR 4 and TNF- $\alpha$ and the mRNA expression levels of $I L-8, T N F-\alpha$ and TLR4 in JEC. This result indicates that GSE assists in the suppression of inflammatory reaction of JEC subjected to heat stress treatment. The immunoregulatory function of GSE can be attributed to its chemical composition. Phenolic compounds in grape seeds have been shown to exert significant anti-inflammatory effects in rats, mice and humans ${ }^{(71,72)}$, with the contributing molecules purported to include flavonols, flavanols and procyanidins (oligomeric flavonoids) ${ }^{(71,73)}$ Bralley et $a l .{ }^{(74)}$ reported that ear inflammation, oedema and polymorphonuclear leucocyte infiltration induced by $12-O-$ tetradecanoylphorbol 13-acetate were inhibited in mice treated for $30 \mathrm{~min}$ with extracts from grape skins and seeds. These findings indicate that phenolic compounds in grapes apparently possess anti-inflammatory activity. The mechanisms responsible for the anti-inflammatory activity of procyanidins have also been investigated in previous studies. Inhibition or reduction of cytokine gene expression may be an important pathway involved in the anti-inflammatory activity of grape phenolic compounds ${ }^{(71,73)}$. Human adipocytes and macrophage-like cell lines have been found to produce low amounts of IL- 6 and monocyte chemotactic protein-1 and high amounts of anti-inflammatory adipokine and adiponectin after pre-treatment with extracts of grape seed procyanidins ${ }^{(71)}$. These results demonstrate that the regulation of the expression of anti-inflammatory and pro-inflammatory cytokines is the primary mechanism responsible for the roles of GSE in the immunoregulatory function of JEC subjected to heat stress treatment.

\section{Epidermal growth factor and epidermal growth factor receptor}

In the present study, the mRNA expression levels of EGF and EGFR in JEC decreased with an increase in culture 
temperature. Liu et al. ${ }^{(12)}$ also observed that under high ambient temperatures, a treatment regimen of $40^{\circ} \mathrm{C}$ for $5 \mathrm{~h}$ per $\mathrm{d}$ over a $10 \mathrm{~d}$ period decreased the mRNA expression levels of $E G F$ and EGFR in porcine small-intestinal epithelia. Previous reports indicate that the expression of EGF and EGFR is related to the damage and recovery of small-intestinal mucosa ${ }^{(75,76)}$. Many investigators have considered that EGF may have no effect on normal intestinal mucosal epithelium, but rather may promote cell proliferation, repair and migration during regeneration following damage ${ }^{(75,76)}$. The signalling cascade mediated by EGFR is characterised by pleiotropy, including cell proliferation, repair and migration, and internal environment stabilisation ${ }^{(75)}$. Therefore, we speculate that the cell proliferation of JEC subjected to heat stress treatment is likely to be decreased, accompanied by a decline in $E G F /$ EGFR gene expression, a hypothesis supported by the observation that the viability of JEC declined in response to an increase in culture temperature.

In the present study, we found that GSE supplementation increased the mRNA expression levels of EGF and EGFR in JEC cultured at 40 or $43^{\circ} \mathrm{C}$. This result indicates that GSE can enhance the growth of normal cells through the activation of EGF-induced signalling pathways. Previous studies have also reported that GSE exhibits the beneficial property of enhancing the growth and viability of normal cells ${ }^{(77)}$ while exhibiting cytotoxicity towards some types of cancer cells ${ }^{(78,79)}$. However, the mechanism by which GSE can distinguish tumour cells from normal cells remains unclear.

\section{Heat shock protein 70}

In present study, the protein concentration of HSP70 in JEC increased with elevated culture temperatures. HSP70 is the most investigated member of a family of proteins synthesised in response to physical, chemical or biological stresses, including heat exposure ${ }^{(80-82)}$. The expression of HSP70 is rapidly up-regulated under conditions of oxidative stress, providing cytoprotection by making cells resistant to otherwise lethal levels of environmental stress ${ }^{(83)}$. There have been many published reports about the protective effects of HSP70 on the intestine under conditions of heat or other stresses in both in vitro and in vivo models ${ }^{(84-86)}$. HSP70 develops a protective interaction with sarco(endo)plasmic reticulum $\mathrm{Ca}^{2+}$ ATPases 2a (SERCA2a) during heat stress, reducing the oxidation and nitrosylation of SERCA2a and thereby increasing its maximal activity ${ }^{(87)}$.

In the present study, GSE supplementation was found to decrease the HSP70 concentration of JEC. Kim et al. ${ }^{(88)}$ also reported that the proteins affected by GSE included those involved in energy generation and protein folding (e.g. HSP60, HSP70 and HSP71, cytoskeletal proteins, and medium-chain and glial fibrillary acidic protein). According to antioxidant capacity and immunity analyses, we speculate that the decline in the expression of HSP70 in heat-induced JEC supplemented with GSE may be closely related to the increase in antioxidant capacity and the decline in inflammatory reactions.

\section{Cell viability}

In the present study, heat stress-induced cytotoxicity was assessed using a cell viability assay, which confirmed that heat stress decreased cell viability. Heat stress has also reportedly been found to decrease cell viability and induce cell death in bovine mammary epithelial cells ${ }^{(89)}$ and hepatic cells of grass carp ${ }^{(90)}$. Heat stress and heat stress-induced oxidative stress have been found to adversely affect the structure and physiology of the cell (e.g. impairing transcription, RNA processing and translation and altering membrane structure $)^{(91,92)}$ and decrease cell viability ${ }^{(89,90)}$. Based on the results of the present study, we speculate that the decreased cell viability of JEC subjected to heat stress treatment may be highly related to changes in antioxidant capacity, inflammatory reaction, HSP70 expression, etc.; however, the underlying mechanisms remain unclear and require further study.

In the present study, GSE supplementation was also found to increase the cell viability of JEC cultured at 40 or $43^{\circ} \mathrm{C}$. Similarly, cocoa phenolic extract has been found to exhibit a remarkable recovery in cell viability after damage induced by tert-butylhydroperoxide ${ }^{(93)}$. However, previous studies have also shown that phenols can significantly impair the viability of human colonic epithelial cells ${ }^{(94)}$. These phenol-induced effects are secondary to changes occurring in the cell membrane resulting in the disruption of tight junction-containing microdomains, and the disruption of these microdomains results in the mislocalisation of tight junction components and altered paracellular permeability ${ }^{(95)}$. In general, previous data on cell viability of humans or animals exposed to plant phenols are inadequate to establish dose-response relationships and further study is required to establish these relationships.

\section{Conclusion}

We report that heat stress decreases the antioxidant capacity of JEC in steers and activates the immune response by up-regulating the expression of anti-inflammatory cytokines in cells. When cultured at 40 and $43^{\circ} \mathrm{C}$, but not at 37 and $46^{\circ} \mathrm{C}$, GSE attenuated the heat stress-induced responses of small-intestinal epithelial cells obtained from a cross-bred steer by increasing the antioxidant capacity and suppressing the immune response. Taken together, we conclude that GSE attenuates the responses of JEC of Simmental $\times$ Qinchuan steers to heat stress, primarily by increasing antioxidant capacity and cell viability and decreasing inflammatory reactions. However, GSE played no role in the regulation of the responses of JEC cultured at normal or extremely high temperatures. Furthermore, a dose-response in vivo study with GSE (based on the doses evaluated in the present study) is required to obtain information regarding the practical physiological and biochemical effects of GSE supplementation, as well as the lowest effective and the highest non-toxic doses of GSE necessary for optimum heat stress studies.

\section{Acknowledgements}

The present study was financially supported by the National Science \& Technology Pillar Program (2012BAD14B18, 
2014BAD08B11 and 2011BAD36B01), which contributed to the study design, study conduct, analysis of the samples and data, and interpretation of the findings, and the National Program on Key Basic Research Project of China (2013CB127303 and 2013CB127304), the Natural Science Foundation Project of CQ CSTC (cstc2013jjB0112 and cstc2012jjA80001), the Fundamental Research Funds for the Central Universities (XDJK2011C030 and XDJK2011B011) and the National Natural Science Foundation of China (30600436), which contributed to the analysis of the samples and data, interpretation of the findings and preparation of the manuscript.

The authors' contributions are as follows: Z. S. and X. L. wrote the initial draft of the manuscript; X. L., Y. Y., C. C., J. Y. and Z. S. implemented and conducted the study, collected the data and analysed the data; Z. S. and S. L. interpreted the data and provided critical comments; S. L. revised the manuscript.

None of the authors has any conflicts of interest to declare.

\section{References}

1. Silanikove N (2000) Effects of heat stress on the welfare of extensively managed domestic ruminants. Livest Prod Sci 67, 1-18.

2. Baumgard RP \& Rhoads LH (2013) Effects of heat stress on postabsorptive metabolism and energetics. Annu Rev Anim Biosci 1, 311-337.

3. Mujahid A, Pumford NR, Bottje W, et al. (2007) Mitochondrial oxidative damage in chicken skeletal muscle induced by acute heat stress. J Poult Sci 44, 439-445.

4. Sahin K, Sahin N, Kucuk O, et al. (2009) Role of dietary zinc in heat-stressed poultry: a review. Poult Sci 88, 2176-2183.

5. Rhoads ML, Kim JW, Collier RJ, et al. (2010) Effects of heat stress and nutrition on lactating Holstein cows: II. Aspects of hepatic growth hormone responsiveness. J Dairy Sci $\mathbf{9 3}$, $170-179$.

6. Baumgart DC \& Dignass AU (2002) Intestinal barrier function. Curr Opin Clin Nutr Metab Care 5, 685-694.

7. Adkins B, Jones M, Bu YR, et al. (2004) Neonatal tolerance revisited again: specific CTL priming in mouse neonates exposed to small numbers of semi- or fully allogeneic spleen cells. Eur J Immunol 34, 1901-1909.

8. Bailey M, Haverson K, Inman C, et al. (2005) The development of the mucosal immune system pre- and post-weaning: balancing regulatory and effector function. Proc Nutr Soc 64 , 451-457.

9. Lambert GP (2009) Stress-induced gastrointestinal barrier dysfunction and its inflammatory effects. J Anim Sci 87 , E101-E108.

10. Yan Y, Zhao Y, Wang H, et al. (2006) Pathophysiological factors underlying heatstroke. Med Hypotheses 67, 609-617.

11. Hall DM, Buettner GR, Oberley LW, et al. (2001) Mechanisms of circulatory and intestinal barrier dysfunction during whole body hyperthermia. Am J Physiol Heart Circ Physiol 280, H509-H521.

12. Liu F, Yin J, Du M, et al. (2009) Heat-stress-induced damage to porcine small intestinal epithelium associated with downregulation of epithelial growth factor signaling. J Anim Sci 87, 1941-1949.

13. Boudry G, Péron V, Huërou-Luron IL, et al. (2004) Weaning induces both transient and long-lasting modifications of absorptive, secretory, and barrier properties of piglet intestine. J Nutr 134, 2256-2262.
14. Lallès JP, Bosi P, Smidt H, et al. (2007) Weaning - a challenge to gut physiologists. Livest Sci 108, 82-93.

15. Beede DK \& Collier RJ (1986) Potential nutritional strategies for intensively managed cattle during thermal stress. J Anim Sci 62, 543-554.

16. Carstens GE, Johnson DE \& Ellenberger MA (1989) Energy metabolism and composition of gain in beef steers exhibiting normal and compensatory growth. In Energy Metabolism of Farm Animals, pp. 131-134 [Y Van Der Honing and WH Close, editors]. Pudoc, Wageningen: European Association for Animal Production, Publication no. 43.

17. Weiss WP, Hogan JS, Todhunter DA, et al. (1997) Effect of vitamin E supplementation in diets with a low concentration of selenium on mammary gland health of dairy cows. J Dairy Sci 80, 1728-1737.

18. Sejian V, Singh AK, Sahoo A, et al. (2013) Effect of mineral mixture and antioxidant supplementation on growth, reproductive performance and adaptive capability of Malpura ewes subjected to heat stress. J Anim Physiol Anim Nutr 95, 252-258.

19. Santos Buelgo C \& Scalbert A (2000) Proanthocyanidins and tannin-like compounds - nature, occurrence, dietary intake and effects on nutrition and health. J Sci Food Agric 80, 1094-1117.

20. Arnous A \& Meyer AS (2008) Comparison of methods for compositional characterization of grape (Vitis vinifera L.) and apple (Malus domestica) skins. Food Bioprod Process 86, $79-86$.

21. Caillet S, Salmiéri S \& Lacroix M (2006) Evaluation of free radical-scavenging properties of commercial grape phenol extracts by a fast colorimetric method. Food Chem 95, 1-8.

22. Uchida S, Edamatsu R, Hiramatsu M, et al. (1987) Condensed tannins scavenge active oxygen radicals. Med Sci Res $\mathbf{1 5}$, 831-832.

23. Yilmaz Y \& Toledo RT (2004) Major flavonoids in grape seeds and skins: antioxidant capacity of catechin, epicatechin, and gallic acid. J Agric Food Chem 52, 255-260.

24. Katiyar SK (2008) Grape seed proanthocyanidins and skin cancer prevention: inhibition of oxidative stress and protection of immune system. Mol Nutr Food Res 52, S71-S76.

25. Sun ZH, Zhang QL, He ZX, et al. (2010) Research on primary culture method for ruminal epithelial and jejunum epithelial cells of goats. Chin J Anim Nutr 22, 602-610.

26. Kaur M, Singh RP, Gu M, et al. (2006) Grape seed extract inhibits in vitro and in vivo growth of human colorectal carcinoma cells. Clin Cancer Res 12, 6194-6202.

27. Roy AM, Baliga MS, Elmets CA, et al. (2005) Grape seed proanthocyanidins induce apoptosis through p53, Bax, and caspase 3 pathways. Neoplasia 7, 24-36.

28. Byth HA, Mchunu BI, Dubery IA, et al. (2001) Assessment of a simple, non-toxic Alamar Blue cell survival assay to monitor tomato cell viability. Phytochem Anal 12, 340-346.

29. Willard HH, Merritt LL, Dean JA, et al. (1981) Ultraviolet and visible absorption methods. In Instrumental Methods of Analysis, 6th ed., pp. 66-104 [HH Willard, LL Merrit, JA Dean and FA Settle, editors]. New York, NY: Van Nostrand.

30. Góth L (1991) A simple method for determination of serum catalase activity and revision of reference range. Clin Chim Acta 196, 143-151.

31. Tang LJ, Tian FZ \& Gao XM (2002) Hepatocellular glycogen in alleviation of liver ischemia-reperfusion injury. Hepatob Pancreat Dis Int 1, 532-535.

32. Islam SN, Hossain KJ, Kamal M, et al. (2004) Serum immunoglobulins and white blood cells status of drug addicts: influence of illicit drugs and sex habit. Addict Biol 9, 27-33. 
33. Murthi P, Fitzpatrick E, Borg AJ, et al. (2008) GAPDH, 185 $r R N A$ and $Y W H A Z$ are suitable endogenous reference genes for relative gene expression studies in placental tissues from human idiopathic fetal growth restriction. Placenta 29, 798-801.

34. Livak KJ \& Schmittgen TD (2001) Analysis of relative gene expression data using real-time quantitative PCR and the $2^{-\Delta \Delta \mathrm{Ct}}$ method. Methods 25, 402-408.

35. Manach C, Williamson G, Morand C, et al. (2005) Bioavailability and bioefficacy of polyphenols in humans. I. Review of 97 bioavailability studies. Am J Clin Nutr 81, Suppl. 1, S230-S242.

36. Rios LY, Bennett RN, Lazarus SA, et al. (2002) Cocoa procyanidins are stable during gastric transit in humans. Am J Clin Nutr 76, 1106-1110.

37. Serra A, Macià A, Romero MP, et al. (2010) Bioavailability of procyanidin dimers and trimers and matrix food effects in in vitro and in vivo models. Br J Nutr 103, 944-952.

38. Martin KR \& Appel CL (2010) Polyphenols as dietary supplements: a double-edged sword. Nutr Dietary Suppl 2, $1-12$.

39. Serra A, Bryant N, Motilva MJ, et al. (2012) Fetal programming of dietary fructose and saturated fat on hepatic quercetin glucuronidation in rats. Nutrition 28, 1165-1171.

40. Fang YZ, Yang S \& Wu GY (2002) Free radicals, antioxidants, and nutrition. Nutrition 18, 872-879.

41. Burke NC, Scaglia G, Saker KE, et al. (2007) Influence of endophyte consumption and heat stress on intravaginal temperatures, plasma lipid oxidation, blood selenium, and glutathione redox of mononuclear cells in heifers grazing tall fescue. J Anim Sci 85, 2932-2940.

42. Lord-Fontaine S \& Averill-Bates DA (2002) Heat shock inactivates cellular antioxidant defenses against hydrogen peroxide: protection by glucose. Free Radic Biol Med 32 , $752-765$.

43. Lin H, De Vos D, Decuypere E, et al. (2008) Dynamic changes in parameters of redox balance after mild heat stress in aged laying hens (Gallus gallus domesticus). Comp Biochem Physiol C Toxicol Pharmacol 147, 30-35.

44. Lin H, Decuypere E \& Buyse J (2006) Acute heat stress induces oxidative stress in broiler chickens. Comp Biochem Physiol A Mol Integr Physiol 144, 11-17.

45. Wang LF, Lin H, Yang QM, et al. (2002) The effect of dietary vitamin A levels on lipid peroxidatic reaction of inoculated and heat stressed laying hens. Acta Vet Zootech Sinica 33, $443-447$

46. Sahin K, Onderci M, Sahin N, et al. (2003) Dietary vitamin C and folic acid supplementation ameliorates the detrimental effects of heat stress in Japanese quail. J Nutr 133, 1882-1886.

47. Mujahid A, Yoshiki Y, Akiba Y, et al. (2005) Superoxide radical production in chicken skeletal muscle induced by acute heat stress. Poult Sci 84, 307-314.

48. Payne RL \& Southern LL (2005) Comparison of inorganic and organic selenium sources for broilers. Poult Sci 84, 898-902.

49. Meyer AS, Yi OS, Pearson DA, et al. (1997) Inhibition of human low-density lipoprotein oxidation in relation to composition of phenolic antioxidants in grapes (Vitis vinifera). J Agric Food Chem 45, 1638-1643.

50. Sato M, Ramarathnam N, Suzuki Y, et al. (1996) Varietal differences in the phenolic content and superoxide radical scavenging potential of wines from different sources. J Agric Food Chem 44, 37-41.

51. Pastrana-Bonilla E, Akoh CC, Sellappan S, et al. (2003) Phenolic content and antioxidant capacity of muscadine grapes. J Agric Food Chem 51, 5497-5503.
52. Ahn HS, Jeon TI, Lee JY, et al. (2002) Antioxidative activity of persimmon and grape seed extract: in vitro and in vivo. Nutr Res 22, 1265-1273.

53. Chis IC, Ungureanu MI, Marton A, et al. (2009) Antioxidant effects of a grape seed extract in a rat model of diabetes mellitus. Diab Vasc Dis Res 6, 200-204.

54. Carpenter R, O'Grady MN, O'Callaghan YC, et al. (2007) Evaluation of the antioxidant potential of grape seed and bearberry extracts in raw and cooked pork. Meat Sci 76, 604-610.

55. Lau DW \& King J (2003) Pre- and post-mortem use of grape seed extract in dark poultry meat to inhibit development of thiobarbituric acid reactive substances. J Agric Food Chem 51, 1602-1607.

56. Mielnik MB, Aaby K \& Skrede G (2003) Commercial antioxidants control lipid oxidation in mechanically deboned turkey meat. Meat Sci 65, 1147-1155.

57. Faria A, Mateus N, de Freitas V, et al. (2006) Modulation of $\mathrm{MPP}^{+}$uptake by procyanidins in Caco- 2 cells: involvement of oxidation/reduction reactions. FEBS Lett 580, 155-160.

58. Soobrattee MA, Neergheena VS, Luximon-Rammaa A, et al. (2005) Phenolics as potential antioxidant therapeutic agents: mechanism and actions. Mut Res Fund Mol Mech Mutagen 579, 200-213.

59. Amico V, Chillemi R, Mangiafico S, et al. (2008) Polyphenolenriched fractions from Sicilian grape pomace: HPLC-DAD analysis and antioxidant activity. Bioresour Technol 99, 5960-5966.

60. Maier T, Schieber A, Kammerer DR, et al. (2009) Residues of grape (Vitis vinifera L.) seed oil production as a valuable source of phenolic antioxidants. Food Chem 112, 551-559.

61. Monagas M, Hernández-Ledesma B, Garrido P, et al. (2005) Quality assessment of commercial dietary antioxidant products from Vitis vinifera L. grape seeds. Nutr Cancer $\mathbf{5 3}$, 244-254.

62. Braunstein J, Qiao L, Autschbach F, et al. (1997) T cells of the human intestinal lamina propria are high producers of interleukin-10. Gut 41, 215-220.

63. Cario E \& Podolsky DK (2000) Differential alteration in intestinal epithelial cell expression of Toll-like receptor 3 (TLR3) and TLR4 in inflammatory bowel disease. Infect Immun $\mathbf{6 8}$, 7010-7017.

64. Cario E, Brown D, McKee M, et al. (2002) Commensalassociated molecular patterns induce selective Toll-like receptor-trafficking from apical membrane to cytoplasmic compartments in polarized intestinal epithelium. $\mathrm{Am} \mathrm{J}$ Pathol 160, 165-173.

65. Gewirtz AT, Navas TA, Lyons S, et al. (2001) Cutting edge: bacterial flagellin activates basolaterally expressed TLR5 to induce epithelial proinflammatory gene expression. J Immunol 167, 1882-1885.

66. Maaser C \& Kagnoff MF (2002) Role of the intestinal epithelium in orchestrating innate and adaptive mucosal immunity. Z Gastroenterol 40, 525-529.

67. Bouchama A, Roberts G, Al Mohanna F, et al. (2005) Inflammatory, hemostatic, and clinical changes in a baboon experimental model for heatstroke. J Appl Physiol 98, 697-705.

68. Leon LR, Blaha MD \& DuBose DA (2006) Time course of cytokine, corticosterone, and tissue injury responses in mice during heat strain recovery. J Appl Physiol 100, $1400-1409$.

69. Wang Q, Guo XL \& Noel G (2007) Heat shock stress ameliorates cytokine mixture-induced permeability by downregulating the nitric oxide and signal transducer and activator of transcription pathways in Caco-2 cells. Shock 27, 179-185. 
70. Hu S, Claud ECEC, Musch MW, et al. (2010) Stress granule formation mediates the inhibition of colonic Hsp70 translation by interferon- $\gamma$ and tumour necrosis factor- $\alpha$. Am J Physiol Gastrointest Liver Physiol 298, G481-G492.

71. Chacóna MR, Ceperuelo-Mallafré V, Maymó-Masipa E, et al. (2009) Grape-seed procyanidins modulate inflammation on human differentiated adipocytes in vitro. Cytokine $\mathbf{4 7}$, 137-142.

72. Panico AM, Cardile V, Avondo S, et al. (2006) The in vitro effect of a lyophilized extract of wine obtained from Jacquez grapes on human chondrocytes. Phytomedicine 13, 522-526.

73. Terra X, Montagut G, Bustos M, et al. (2009) Grapeseed procyanidins prevent low-grade inflammation by modulating cytokine expression in rats fed a high-fat diet. J Nutr Biochem 20, 210-218.

74. Bralley EE, Hargrove JL, Greenspan P, et al. (2007) Topical anti-inflammatory activities of Vitis rotundifolia (muscadine grape) extracts in the tetradecanoylphorbol acetate model of ear inflammation. J Med Food 10, 636-642.

75. Helmrath MA, Shin CE \& Erwin CR (1998) Intestinal adaptation is enhanced by epidermal growth factor independent of increased ileal epidermal growth factor receptor expression. J Pediatr Surg 33, 980-985.

76. Nair RR, Warner BB \& Warner BW (2008) Role of epidermal growth factor and other growth factors in the prevention of necrotizing enterocolitis. Semin Perinatol 32, 107-113.

77. Bagchi D, Bagchi M, Stohs SJ, et al. (2000) Free radicals and grape seed proanthocyanidin extract: importance in human health and disease prevention. Toxicology 148, 187-197.

78. Sharma G, Tyagi AK, Singh RP, et al. (2004) Synergistic anti-cancer effects of grape seed extract and conventional cytotoxic agent doxorubicin against human breast carcinoma cells. Breast Cancer Res Treat 85, 1-12.

79. Meeran SM \& Katiyar SK (2007) Grape seed proanthocyanidins promote apoptosis in human epidermoid carcinoma A431 cells through alterations in Cdki-Cdk-cyclin cascade, and caspase- 3 activation via loss of mitochondrial membrane potential. Exp Dermatol 16, 405-415.

80. Deane EE \& Woo NYS (2005) Cloning and characterization of the hsp70 multigene family from silver sea bream: modulated gene expression between warm and cold temperature acclimation. Biochem Biophys Res Commun 330, 776-783.

81. Tyagi A, Agarwal R \& Agarwal C (2003) Grape seed extract inhibits EGF-induced and constitutively active mitogenic signaling but activates JNK in human prostate carcinoma DU145 cells: possible role in antiproliferation and apoptosis. Oncogene 22, 1302-1316.
82. Staib JL, Quindry JC, French JP, et al. (2007) Increased temperature, not cardiac load, activates heat shock transcription factor 1 and heat shock protein 72 expression in the heart. Am J Physiol Regul Integr Comp Physiol 292, R432-R439.

83. Kampinga HH (1993) Thermotolerance in mammalian cells. Protein denaturation and aggregation, and stress proteins. J Cell Sci 104, 11-17.

84. Wischmeyer PE, Musch MW, Madonna MB, et al. (1997) Glutamine protects intestinal epithelial cells: role of inducible HSP70. Am J Physiol 272, G879-G884.

85. Ren H, Musch MW, Kojima K, et al. (2001) Short fatty acids induce intestinal epithelial heat shock protein 25 and IEC 18 cells. Gastroenterology 121, 631-639.

86. Ohkawara T, Nishihira J, Takeda H, et al. (2006) Protective effect of geranylgeranylacetone on trinitrobenzene sulfonic acid-induced colitis in mice. Int J Mol Med 17, 229-234.

87. Fu MH \& Tupling AR (2009) Protective effects of Hsp70 on the structure and function of SERCA2a expressed in HEK-293 cells during heat stress. Am J Physiol Heart Circ Physiol 296, H1175-H1183.

88. Kim H, Deshane J, Barnes S, et al. (2006) Proteomics analysis of the actions of grape seed extract in rat brain: technological and biological implications for the study of the actions of psychoactive compounds. Life Sci 78, 2060-2065.

89. Du J, Di H-S, Guo L, et al. (2008) Hyperthermia causes bovine mammary epithelial cell death by a mitochondrialinduced pathway. J Therm Biol 33, 37-47.

90. Cui YT, Liu B, Xie J, et al. (2013) The effect of hyperthermia on cell viability, oxidative damage, and heat shock protein expression in hepatic cells of grass carp (Ctenopharyngodon idellus). J Thermal Biol 38, 355-361.

91. Iwagami Y (1996) Changes in the ultrastructure of human cells related to certain biological responses under hyperthermic culture conditions. Hum Cell 9, 353-366.

92. Sahin K, Orhan C, Akdemir F, et al. (2011) Tomato powder supplementation activates Nrf-2 via ERK/Akt signaling pathway and attenuates heat stress-related responses in quails. Anim Feed Sci Technol 165, 230-237.

93. Martín MÁ, Ramos S, Cordero-Herrero I, et al. (2013) Cocoa phenolic extract protects pancreatic beta cells against oxidative stress. Nutrients 5, 2955-2968.

94. Pedersen GBJ \& Saermark T (2002) Phenol toxicity and conjugation in human colonic epithelial cells. Scand $J$ Gastroenterol 37, 74-79.

95. McCall IC, Betanzos A, Weber DA, et al. (2009) Effects of phenol on barrier function of a human intestinal epithelial cell line correlate with altered tight junction protein localization. Toxicol Appl Pharmacol 241, 61-70. 